\title{
Considering the Impacts of Metal Depletion on the European Electricity System
}

\author{
Lei Xu ${ }^{1,2}$, Zongfei Wang ${ }^{2}\left(\mathbb{C}\right.$, Hasan Ümitcan Yilmaz ${ }^{2}$, Witold-Roger Poganietz ${ }^{1, *}$, Hongtao Ren ${ }^{3}$ and Ying Guo $^{4}$ \\ 1 Institute for Technology Assessment and Systems Analysis (ITAS), Karlsruhe Institute of Technology (KIT), \\ Karlstraße 11, 76133 Karlsruhe, Germany; lei.xu@kit.edu \\ 2 Institute for Industrial Production (IIP), Chair of Energy Economics, Karlsruhe Institute of Technology (KIT), \\ Hertzstraße 16, Building 06.33, 76187 Karlsruhe, Germany; zongfei.wang@partner.kit.edu (Z.W.); \\ hasan.yilmaz@kit.edu (H.Ü.Y.) \\ 3 School of Business, East China University of Science and Technology, Meilong Road 130, \\ Shanghai 200237, China; ren@ecust.edu.cn \\ 4 School of Energy Science and Engineering, Central South University, Lushan South Road 932, \\ Changsha 410083, China; guoying2000@foxmail.com \\ * Correspondence: witold-roger.poganietz@kit.edu; Tel.: +49-721-608-28180
}

Citation: Xu, L.; Wang, Z.; Yilmaz, H.Ü.; Poganietz, W.-R.; Ren, H.; Guo, Y. Considering the Impacts of Metal Depletion on the European Electricity System. Energies 2021, 14, 1560. https://doi.org/10.3390/en14061560

Academic Editor: Dalia Štreimikienè

Received: 23 November 2020

Accepted: 8 March 2021

Published: 11 March 2021

Publisher's Note: MDPI stays neutral with regard to jurisdictional claims in published maps and institutional affiliations.

Copyright: (c) 2021 by the authors. Licensee MDPI, Basel, Switzerland. This article is an open access article distributed under the terms and conditions of the Creative Commons Attribution (CC BY) license (https:// creativecommons.org/licenses/by/ $4.0 /)$.

\begin{abstract}
The transformation of the European electricity system could generate unintended environmentrelated trade-offs, e.g., between greenhouse gas emissions and metal depletion. The question thus emerges, how to shape policy packages considering climate change, but without neglecting other environmental and resource-related impacts. In this context, this study analyzes the impacts of different settings of potential policy targets using a multi-criteria analysis in the frame of a coupled energy system and life cycle assessment model. The focus is on the interrelationship between climate change and metal depletion in the future European decarbonized electricity system in 2050, also taking into account total system expenditures of transforming the energy system. The study shows, firstly, that highly ambitious climate policy targets will not allow for any specific resource policy targets. Secondly, smoothing the trade-off is only possible to the extent of one of the policy targets, whereas, thirdly, the potential of recycling as a techno-economic option is limited.
\end{abstract}

Keywords: system expenditures; climate change; metal depletion; multi-criteria analysis; LCA; electricity system model

\section{Introduction}

Slowing down climate change is one of the main societal drivers of the transformation of the European energy system from a conventional fossil-based to a decarbonized sustainable energy supply [1]. Whereas energy policies as instruments to implement societal aims are of great significance to drive the transformation, energy policy generally uses energy system models (ESMs) for advice regarding the adequate shape of the future energy system. The mainstream approach of modeling energy systems is to minimize the total system expenditures while constraining $\mathrm{CO}_{2}$ or greenhouse gas (GHG) emissions [2,3].

Nevertheless, an increasing amount of research highlights the importance of nonclimate environmental and resource-related impacts of the transformation, which could generate unintended trade-offs [4-6]. With the transformation to a decarbonized energy system, co-benefits could be expected, such as a decreased dependency on fossil fuels or lower eutrophication, but potentially important trade-offs could emerge, like an increased requirement for metal resources [4]. According to $\mathrm{Xu}$ et al. [4], in scenario High-RES Cen, reduced life-cycle GHG emissions of the European electricity system of $84 \%$ in 2050, compared to 2014, would raise metal depletion by about 235\%. Metal depletion accounts for the system's demand for primary metal [7]. The findings refer to "bulk" metals, like steel and iron, and do not consider strategic metals. The main reasons for the trade-off are the low full load hours, and the small size of renewable energy power plants per generated 
kWh electricity compared to power plants using fossil fuels or uranium, indicating a negative scale effect when comparing conventional and renewable energy technologies in respect to metal requirements [4].

Correspondingly, the EU discusses and implements strategies to maintaining metal availability and accessibility through, amongst others, trade agreements with exporting countries and recycling $[8,9]$. The long-term aim is to secure the trade connections while reducing import dependency; but environmental considerations also play a role in these considerations [10].

Bearing in mind these additional impacts of the transformation process towards a renewable energies-based electricity system, from a policy perspective, the question emerges of how to shape a future electricity system which is climate neutral, environmentally friendly, and economically sound. What policy packages could serve to attain which different policy targets, such as an ambitious climate policy in combination with an aspiring resource policy? A policy package combines different single policy measures, aimed at addressing one or more policy targets [11-14]. The rationale is "to improve the impacts of the individual policy measures, minimize possible negative side effects, and/or facilitate interventions' implementation and acceptability" [12].

ESMs, as the main instrument to support energy policies, seldom address non-energy resource demands. Additionally, due to their generally single-objective perspective, they cannot elaborate different policy aims, and thus potential trade-offs, accordingly [2,3]. To analyze the above-mentioned question, extending the scope of ESMs, as well as using a multi-objective perspective, seems to be necessary.

Combining ESMs with life cycle assessment (LCA) has been identified as a suitable approach to broaden the scope of the analyses through including additional environmental and resource-related impacts $[4-6,15]$. Furthermore, the combination of both approaches allows switching from a direct emission perspective to a life-cycle perspective. Not only the direct emissions and resource demands of the electricity system under review are taken into account, but also those emissions and resource requirements of the upstream sectors induced by the electricity system. Recent literature has discussed performing trade-off analysis by applying such an approach. However, most research conducts expost LCA analysis to assess the trade-offs in terms of environment, resources, and other aspects connected to energy system pathways, calculated by ESMs [4-6,15-17]. Those studies fail to provide knowledge-based information on potentially feasible and effective solutions to balance trade-offs between policy targets. Only a few studies have focused on integrating LCA indicators to ESMs [18-21]. However, these studies either follow the ex-post assessment approach $[18,19]$, or aggregate all considered environmental impacts into only one or a few indicators [20,21], though a multi-objective optimization approach is applied. None of them has thoroughly analyzed the potential impacts on the shape of the electricity system if the trade-offs are implemented in respective policies.

The high-level objective of the presented study is to analyze the impacts of different outlines of policy packages, which address both climate and resource policy targets, on the shape of the European electricity system in the year 2050. The analysis will make use of a multi-criteria analysis in combination with a coupled ESM-LCA model. Although the focus of the study is on the interrelationship between climate policy and resource policy, the analysis also includes system expenditures, as an additional factor addressed in political and societal discussions.

The paper is organized as follows: Section 2 introduces the methodological framework, data, and the scenarios representing different policy packages. Section 3 presents the results and conducts a comparative analysis of the defined scenarios. The findings are discussed in Section 4; Section 5 offers some concluding remarks.

\section{Methods}

The methodological framework consists of an algebraic model, which couples the energy system model PERSEUS-EU with an LCA model into the LCA-PERSEUS-EU model, 
with a multi-objective formulation, and the scenarios used for the analyses. PERSEUS strands for "Programme-package for Emission Reduction Strategies in Energy Use and Supply-Certificate Trading". The chosen methodological frame allows for identification of the best solution for different sets of societal-relevant objectives, as discussed in the introduction (Section 1), considering important technological, political, and environmental constraints.

\subsection{Energy System Model PERSEUS-EU}

PERSEUS-EU [22-24] is a long-term energy system optimization model of the European electricity system. The model consists of the EU27 (without the islands of Cyprus and Malta), but includes Switzerland, Norway, and the United Kingdom, i.e., in total 28 states. The objective of the optimization is to minimize all decision-relevant expenditures. The expenditures are composed of the fuel costs, the costs for emitting $\mathrm{CO}_{2}$, other operating costs, as well as investment costs of electricity generation units, to thereby simulate economic decision-making behavior. The objective function is complemented by restrictions addressing technological, political, and environmental constraints. The optimization is driven by the restriction to satisfy the exogenously given electricity demand. The most important decision variables are electricity production capacities, electricity production levels, and electricity exchanges between the modeled European countries. The time horizon of the model is 2050. PERSEUS-EU is implemented in GAMS, the programming language for writing mathematical optimization problems, and is solved with the CPLEX solver, a solution algorithm for large scale mixed integer linear programming problems. $\mathrm{CO}_{2}$ and energy carrier costs are based on [25]. Techno-economic parameters of the investment options are from [26]. The investment expenditures of renewable energy sources are based on [27]. The existing power plant portfolio of the European countries are modeled using the WEPP database [28].

\subsection{Life Cycle Assessment and the Coupled Model LCA-PERSEUS-EU}

LCA is defined by the International Organization for Standardization as a method to evaluate the input, output, and the potential environmental impacts of a product system throughout the entire lifespan, i.e., from extraction of resources, manufacturing and processing, transportation, use of the product, to disposal management [29]. An LCA includes four phases: goal and scope, inventory analysis, impact assessment, and interpretation. The target product system of the LCA analysis is the European electricity system, consistent with the PERSEUS-EU model. The goal is to provide environmental and resource-related indicators to the PERSEUS-EU model. The life cycle inventory (LCI) makes use of the Ecoinvent 3.3 database [30], as well as of the findings of the ReFlex project [17]. The ReFlex project implemented the learning curve approach in process models, as well as expectations about photovoltaic cells (PV) and wind power technologies expectable in the future. The calculations of the LCI of the year 2050 make use of these assumptions. The functional unit of each electricity generation technology is one MWh. The identified emissions assigned to the technologies, as they are modeled in the LCI, are assessed using the assessment approach ReCiPe [31]. The GHG emissions and metal depletion by main technologies from 2015 to 2050 are presented in Table A1 [17]. The phase of interpretation allows for checking and evaluating the results to guarantee their reliability. The coupling of the LCA model with PERSEUS-EU applies the Environmental Assessment Framework for Energy System Analysis (EAFESA). EAFESA is a guide for coupling ESM and LCA models to handle the challenges due to the differences of both approaches with regard to the system boundaries, databases, and assumptions [4].

\subsection{Augmented $\varepsilon$-Constraint}

The multi-objective analysis applies the $\varepsilon$-constraint method [32]. The $\varepsilon$-constraint method uses all but one objective function as secondary conditions in addition to the abovementioned technological, political, and environmental constraints, optimizing the selected 
objective function. However, since the conventional $\varepsilon$-constraint approach fails to guarantee efficient solutions (i.e., Pareto-optimal solution), an augmented version of the method is used in this study. Pareto-optimality refers to a solution in which an improvement of one criterion is not possible without worsening the performance of at least one other criterion [33].

The augmented version of the method sees the implementation of slack variables related to those objective functions, which are used as constraints. In our case, the selected objective function minimizes the total system expenditures (EX). The objective functions used as additional constraints are GHG emissions addressing climate change (CC), and metal demand addressing metal depletion (MD). Thus, the optimization problem looks as follows:

$$
\text { Minimize }\left(f_{E X}(x)-\delta \times\left(s_{C C} / r_{C C}+s_{M D} / r_{M D}\right)\right) \text {. }
$$

Subject to:

$$
\begin{gathered}
f_{C C}(x)+s_{C C}=e_{C C}, \\
f_{M D}(x)+s_{M D}=e_{M D},
\end{gathered}
$$

where $f_{E X}(x)$ represents all decision-relevant expenditures. $\delta$ is an auxiliary parameter, which is generally small, e.g., $10^{-3} \cdot r_{C C}$ and $r_{M D}$ give the range of the objective functions regarding $C C$ and $M D$, respectively. $s_{C C}$ and $s_{M D}$ are the slack variables to force the model to produce only efficient solutions, which drives the model to look for the optimal solution of Equation (1). They are non-negative variables related to CC and MD, respectively. Equation (2) and Equation (3) are the constrained objective functions for CC and MD, respectively. $e_{C C}$ and $e_{M D}$ define the upper limits for GHG emissions and metal demand, respectively. $f_{C C}(x)$ and $f_{M D}(x)$ are positive variables representing the amounts of GHG emissions and metal depletion within the entire system, respectively.

The augmented version of the $\varepsilon$-constraint method allows for optimal solutions with GHG emissions and metal depletion below the given upper limit, i.e., below $e_{C C}$ and $e_{M D}$, respectively.

\subsection{Scenarios}

To analyze the consequences of different shapes of policy packages, which represent altered decision-making preferences regarding climate change and metal depletion, a couple of scenarios are defined. Hereby, each scenario represents a potential policy package. The combination of the upper limits, $e_{M D}$ and $e_{c c}$, characterizes one scenario.

To identify the upper limits, first, a payoff table is calculated by minimizing separately the system expenditures (EX), GHG emissions (CC), and metal depletion (MD), to determine the best and worst solutions regarding the three objectives. For each objective optimization, the other two objectives are relaxed. The combined best solution of the three calculations regarding GHG emissions and metal depletion defines the utopia point and is set to $0 \%$. The combined worst solution is the nadir point and is set to $100 \%[34,35]$.

In the second step, the ranges between the utopia and nadir points of CC and MD obtained describe the upper limits regarding GHG emissions and metal depletion, i.e., $e_{M D}$ and $e_{c c}$, respectively. For the analysis, three different policy ambitious levels are defined, each reflecting hypothetical decision-making preferences. For each ambitious level, an upper limit is set. Hereby, the three intermediate equidistant grid points between the utopia and nadir points specify the limits. The most ambitious policy strives to realize $25 \%$ of the difference between the utopia and the nadir points. To derive the aspired GHG emissions or metal depletion, the calculated value is added to the utopia value. The moderate policy aims at $50 \%$, and a relaxed policy is content with $75 \%$ of the difference between the utopia and nadir points. The ranges of CC and MD are divided into four equal intervals by three intermediate equidistant grid points (i.e., $25 \%, 50 \%$, and $75 \%$ ) that are used to vary parametrically $e_{C C}$ and $e_{M D}$. This means policy is able to control the electricity system in a way that guarantees the respective upper limits in each scenario. 
The main driver to transform the European energy system is to slow down climate change. Thus, in all scenarios the $\mathrm{CO}_{2}$ price is set to $160 € / \mathrm{t} \mathrm{CO}$ in 2050 , according to the 450 ppm scenario of World Energy Outlook [25]. To reflect different decision-making preferences, the precise GHG emission targets will vary between the scenarios, allowing for less ambitious climate policies. However, to emphasize the current societal environment, which strives for slowing down climate change, the upper limit of $e_{c c}$. is limited to $50 \%$. Policy packages allowing for a relaxed preference for slowing down climate change will be not scrutinized in this study.

Consequently, six scenarios are defined in the following policy package. These are: (1) CC ambitious and MD ambitious (CAMA), (2) CC ambitious and MD moderate (CAMM), (3) CC ambitious and MD relaxed (CAMR), (4) CC moderate and MD ambitious (CMMA), (5) CC moderate and MD moderate (CMMM), and (6) CC moderate and MD relaxed (CAMR). For comparison, the results obtained from single objective optimizations are often called selfish scenarios [35]. These are EX selfish in case of minimizing the system expenditures, CC selfish for minimizing the GHG emissions, and MD selfish for minimizing metal depletion. Table 1 summarizes the definition of the three selfish scenarios and the six policy package scenarios with different decision-making preferences.

Table 1. Definition of the scenarios with different decision-making preferences.

\begin{tabular}{cccccc}
\hline & \multicolumn{5}{c}{ Ranges of Decision-Making Preferences } \\
\cline { 2 - 6 } Scenario & $\begin{array}{c}\text { Utopia } \\
\mathbf{( 0 \% )}\end{array}$ & $\begin{array}{c}\text { Ambitious } \\
\mathbf{( 2 5 \% )}\end{array}$ & $\begin{array}{c}\text { Moderate } \\
\mathbf{( 5 0 \% )}\end{array}$ & $\begin{array}{c}\text { Relaxed } \\
\mathbf{( 7 5 \% )}\end{array}$ & $\begin{array}{c}\text { Nadir } \\
\mathbf{( 1 0 0 \% )}\end{array}$ \\
\hline EX selfish & EX & & & \\
CC selfish & CC & & & \\
MD selfish & MD & CC, MD & MD & \\
CAMA & & CC & MD \\
CAMM & \multicolumn{7}{c}{ CC } \\
CAMR & \multicolumn{5}{c}{ CC, MD } \\
CMMA & \multicolumn{5}{c}{ CC } \\
CMMM & \multicolumn{5}{c}{ MD } \\
CMMR & \multicolumn{5}{c}{}
\end{tabular}

\section{Results}

The payoff table obtained by the optimization of the single objectives defines a "skewed" triangle in which all mathematically feasible solutions can be located. The corner points of the triangle regarding system expenditures, metal depletion, and climate change are set by the scenarios CC selfish - the first two corner points-and MD selfishthe last one (see Table 2). The EX selfish scenario is within that triangle, with the lowest system expenditures, while GHG emissions and metal depletion are in between the other two selfish scenarios.

Table 2. Payoff table obtained by the optimizations of a single objective.

\begin{tabular}{|c|c|c|c|}
\hline & EX $\left(10^{12} €\right)$ & $\mathrm{CC}\left(10^{13} \mathrm{~kg} \mathrm{CO} \mathrm{Cq}_{2}\right)$ & $\mathrm{MD}\left(10^{12} \mathrm{~kg} \mathrm{Fe}\right.$ eq $)$ \\
\hline EX selfish & 3.10 & 3.08 & 1.93 \\
\hline CC selfish & 9196 & 0.74 (utopia) & 2.20 (nadir) \\
\hline MD selfish & 8.42 & 8.54 (nadir) & 0.47 (utopia) \\
\hline
\end{tabular}

Note: The figures are the outcome of several model runs using different objective functions as described in Section 2.4. The "utopia" figure gives the lowest possible value, and the "nadir" the highest possible value, regarding GHG emissions and metal depletion, achieved by minimizing GHG emissions or metal depletion, respectively.

Striving solely to slow down climate change (scenario CC selfish) leads, naturally, to the lowest GHG emissions of all selfish scenarios. Consequently, the scenario CC selfish shows the highest metal depletion level, setting the nadir point in respect to metal depletion. 
However, the expenditures are around three thousand times higher than that in the EX selfish scenario, and a thousand times higher than that in the MD selfish scenario. The very high difference between the selfish scenarios regarding expenditures stems mainly from the necessity to invest excessively in low-carbon renewable energy sources (RES) technologies, e.g., wind power plants, to achieve the lowest possible GHG emission level while securing a reliable electricity supply. The high investments in RES technologies are at the expense of dispatchable technologies. The high expenditure in the CC selfish scenario accounts for low storage technology investments, since the model assumes only pumped storage (PSP) technologies.

A world with a high preference for low metal depletion, i.e., scenario MD selfish, would result in the highest GHG emissions of all selfish scenarios, defining the nadir point, but clearly the lowest metal depletion, the utopia point. Comparing the scenario CC selfish with the scenario MD selfish confirms, from a different angle, the strong trade-off relation between climate policy and resource policy.

Of the six identified policy package scenarios, the two most ambitious scenarios (CAMA and CAMM) result in no mathematically feasible solutions. The model assumes a reliable electricity supply, satisfying the electricity demand at each model time-slice. Since demand responses or power-to-gas technologies are not modeled in hours in which RES cannot match electricity demand, the supply gap has to be closed by gas-fired power plants and pumped storage power plants. Due to the restricted investment opportunities regarding pumped storage power plants, gas-fired power plants must be dispatched. However, setting the GHG emission target, which corresponds to an ambitious decisionmaking preference regarding climate, i.e., GHG emissions of about $2.69 \times 10^{13} \mathrm{~kg} \mathrm{CO}_{2}$ eq, demands a specific mix of renewable energy technologies that corresponds to metal depletion, which goes beyond the level of $1.34 \times 10^{12} \mathrm{~kg}$ Fe eq, which equals an ambitious level of $50 \%$.

Figure 1 plots the relationship between the system expenditures, GHG emissions, and metal depletion for the scenarios with mathematically feasible solutions. The Appendix A lists the corresponding figures (Table A2).

In contrast to the significant differences in respect to the system expenditures between CC selfish and MD selfish scenarios on the one side, and the EX selfish scenario on the other, the discrepancies between the policy package scenarios is comparably small. CMMR shows $0.3 \%$, CAMR 2\%, CMMM 8\%, and CMMA 23\% higher expenditures, compared to the EX selfish scenario.

The high costs of achieving the CC selfish scenario level emerge mainly when pursuing from the ambitious level (25\%) to the utopia level (0\%). Reducing the ambitious level of the climate policy will reduce the system expenditures notably, compared to the CC selfish scenario. The system expenditures would drop to at least $0.0079 \%$ of the CC selfish system expenditures. The corresponding scenario CAMR is the policy package scenario with the highest system expenditures. Any relaxing of the climate policy targets would allow installing base load energy technologies with higher life-cycle greenhouse gas emissions per generated $\mathrm{kWh}$, reducing the necessity of RES technologies.

The system expenditures of the MD selfish scenario are higher by a factor of $2.7 \mathrm{com}-$ pared to the EX selfish scenario. Relaxing the ambition level of the resource policy would not have the same noteworthy impact on the relative expenditures as a reduced climate change policy ambition. The expenditures of the corresponding scenario CAMR reaches $12.8 \%$ of the expenditures of the MD selfish scenario.

A relaxed preference for slowing down climate change could achieve significant expenditure savings while still being ambitious from either a climate or a resource-related perspective (see CAMR and CMMA). As mentioned above, the model allows only PSP for storage systems. Implementing other, on average less costly storage systems, the "cost jump" should be less pronounced. The size of the drop depends on the average investment and operating costs of the storage systems, as well as the total size of unrequired RES 
plants. However, available data of grid-connected storage power plants are subject to large uncertainties, and thus were not included.

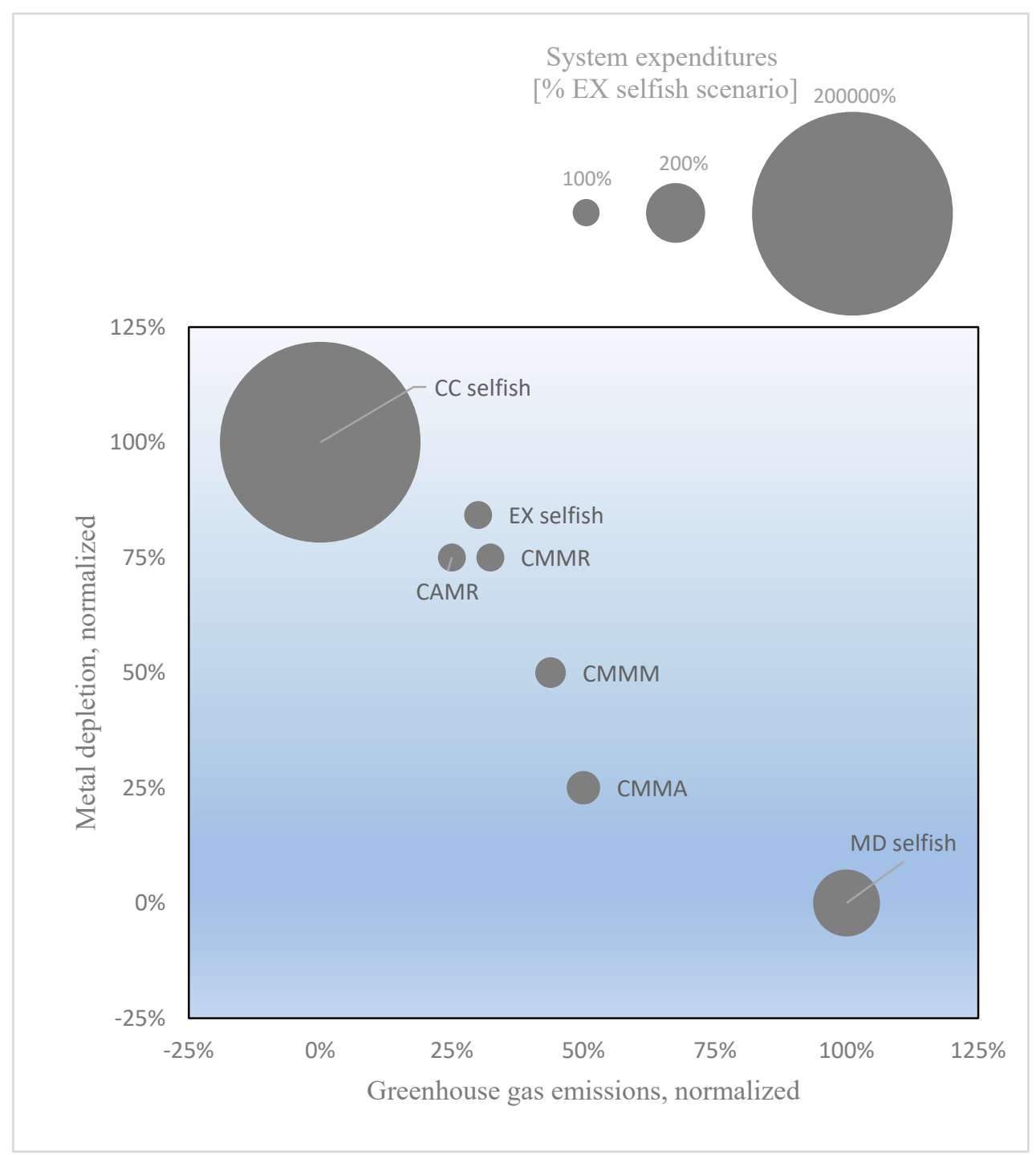

Figure 1. Relationship between system expenditures, GHG emissions, and metal depletion. The marker area is proportional to system expenditures. The GHG emissions and metal depletion are normalized to the range between the utopia and nadir points, $0-100 \%$.

Comparing CAMR with CMMR, i.e., enhancing the preference for slowing down climate change from a moderate level (32\%) to an ambitious level $(25 \%)$ while realizing a relaxed resource policy preference $(75 \%)$, would lead to increased expenditures of $2 \%$. Raising the preference for a lower metal depletion from a moderate level $(50 \%)$ to an ambitious level $(25 \%)$ while maintaining the preference for slowing down climate change at the moderate level, i.e., comparing CMMA with CMMR, would cause higher expenditures of $14 \%$. It seems that the system expenditures are more sensitive to metal depletion than to climate change, as long as only policy package scenarios are considered. This is mainly because a high $\mathrm{CO}_{2}$ price has already been set for all considered scenarios.

Taking into account the GHG emissions and the metal depletion of the scenario EX selfish as the bottom line, only scenario CAMR would see improvements to the situation. The GHG emissions would decrease by $13 \%$ and metal depletion by $8 \%$. Enhancing the preference for decreasing metal depletion further would sacrifice the performance of GHG emissions. However, climate change is an inactive constraint in the scenarios CMMM and 
CMMR. The actual GHG emissions are lower than the possible maximum upper limit. Relaxing the climate policy from ambitious to moderate without changing the ambitious level of the resource policy would induce an increase of the GHG emission of 7\%-points, compared to the ambitious climate policy, even though the maximum upper limit for a moderate ambition would allow an increase of the GHG emissions by $25 \%$-points. This leads to a non-linear trade-off between the impacts of climate policy and resource policy (Figure 2). Increasing the ambition of the resource policy, i.e., reducing metal depletion, would not lead to a corresponding growth of the GHG emissions.

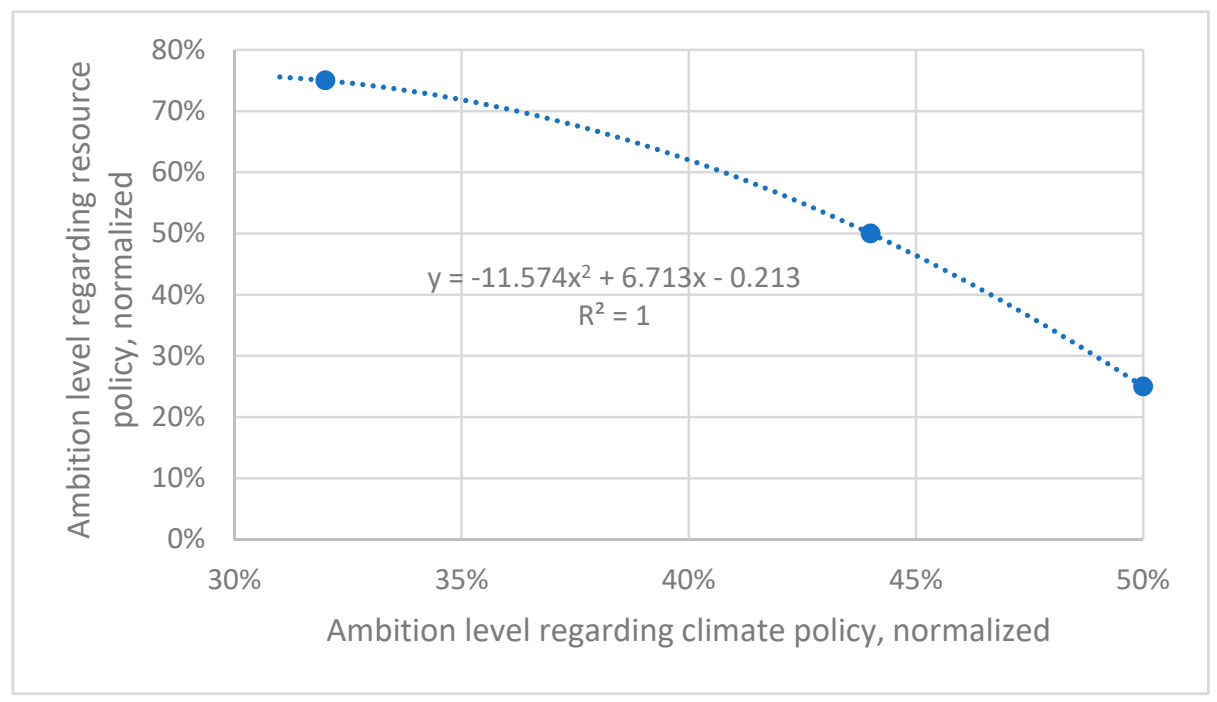

Figure 2. Trade-off between climate policy and resource policy in the policy package scenarios.

Summing up, using the EX selfish scenario as a reference, of all mathematically feasible policy package scenarios, the CAMR scenario is the only one which sees improvements of both GHG emissions and metal depletion. The GHG emissions would drop by $13 \%$ and metal depletion by $8 \%$; but CAMR is $2 \%$ more expensive. The CMMM scenario combines both moderate policy ambitions. Compared to the EX selfish scenario, the CMMM reduces metal depletion by $31 \%$, but raises GHG emissions and system expenditures by $36 \%$ and $8 \%$, respectively. The CMMA scenario with a rather strong preference for resource policy, results in a drop of metal depletion of $53 \%$, but emits $51 \%$ more GHG emissions and is $23 \%$ more expensive.

Understanding the effects of taking into account resource policy in shaping an optimal energy system requires a detailed comparison of the different scenarios. Figure 3 shows the resulting electricity mix in 2050 of the scenarios with mathematically feasible solutions.

In the EX selfish scenario, the shape of the electricity mix in 2050 is determined by the relative generation costs of each energy technology when considering electricity production capacities, electricity production levels, and electricity exchanges between the modelled European countries, as well as a $\mathrm{CO}_{2}$ price of $160 € / \mathrm{t} \mathrm{CO}$. In this scenario, coal and lignite power plants are completely crowded out. The main energy technologies are PVs with $26 \%$ share of the entire electricity generation, wind onshore (20\%), and wind offshore (9\%). To balance the fluctuating supply of electricity, gas-fired power plants with a share of $14 \%$ of the electricity mix are required, supported by PSP as the sole storage system. Hydropower $(16 \%)$ and nuclear power plants $(11 \%)$ provide base load.

In the case of the CC selfish scenario, the electricity mix is set by the life-cycle GHG emissions of each energy technology. Since wind power plant shows the lowest GHG emissions per produced $\mathrm{kWh}$, the share of both technologies reaches $37 \%$ (wind onshore) and $34 \%$ (wind offshore), respectively. To balance the fluctuating supply of electricity, only hydropower $(17 \%)$ and nuclear power $(11 \%)$ plants are installed; energy carriers with quite low life-cycle GHG emissions. Under these conditions, PV, which has higher GHG 
emissions than wind power, is not required. Notwithstanding, all fossil-based power plants are also no longer required.

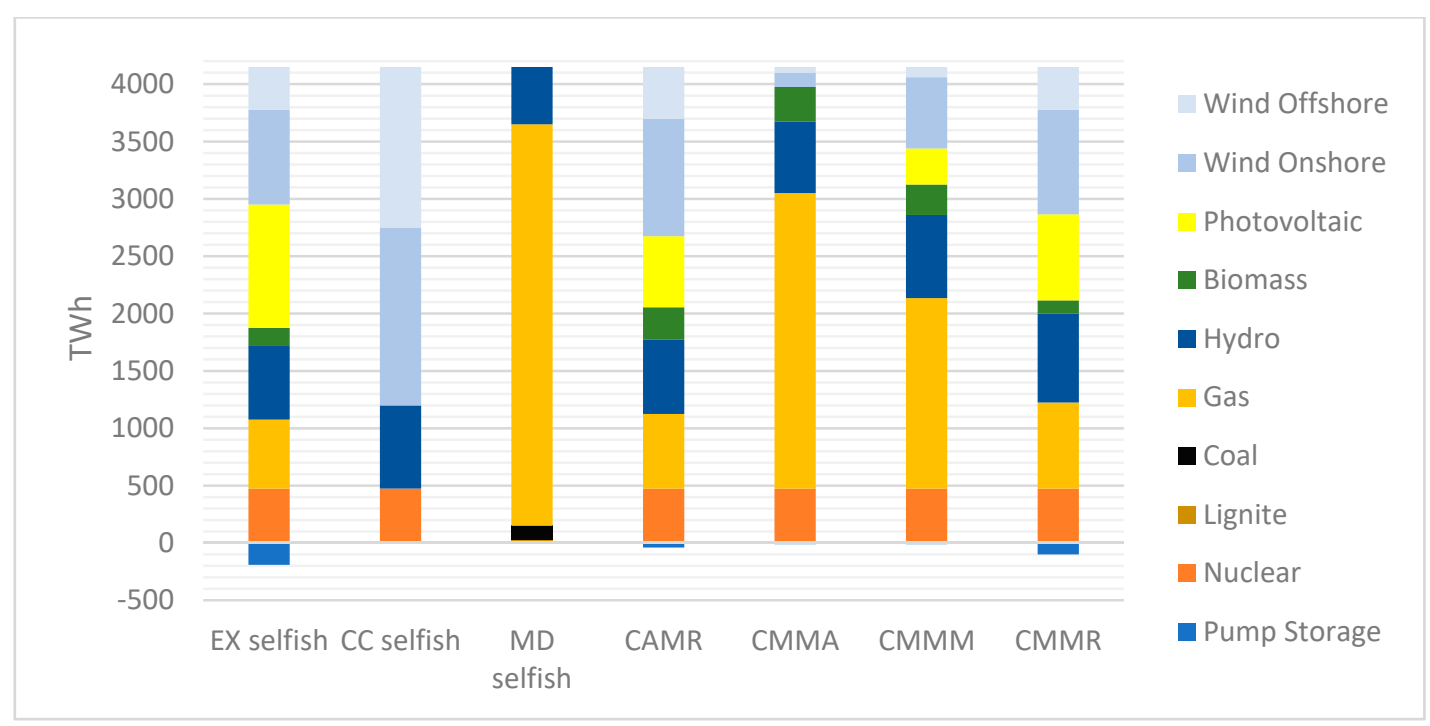

Figure 3. Electricity mix in 2050 of the scenarios with feasible solutions.

Minimizing life-cycle metal depletion leads to a complete reverse of the electricity mix compared to the scenarios EX selfish and CC selfish. In the MD selfish scenario gas-fired power plants will contribute $84 \%$ of the electricity generation, since gas-fired power plants show the lowest metal depletion per produced $\mathrm{kWh}$. The other technologies with low metal depletion are hydropower (12\% share), coal (3\%) and lignite (1\%).

Available capacities limit the share of nuclear power in the scenarios EX selfish and CC selfish. In addition, a large part of the hydropower is retained in all scenarios. These results hold in all scenarios, with the exception of the MD selfish scenario, where the metal depletion target leads to a negligible share of nuclear and the lowest share of hydropower in the electricity mix in all scenarios.

Introducing a metal depletion target affects the electricity mix quite significantly. Combining an ambitious climate change target with a relaxed metal depletion target, as assumed in the CAMR scenario, reduces the shares of wind power, compared to the scenario CC selfish, to $25 \%$ (wind onshore) and 11\% (wind offshore), whereas the share of gas-fired power plants increases to $16 \%$. PV contributes $15 \%$ to the electricity production. Compared to the EX selfish scenario, the shares in the CAMR scenario are higher in respect to wind power plants.

The relevance of metal depletion targets for the electricity mix is also obvious in the case of a moderate climate policy target. A combination of a moderate climate policy with an ambitious resource policy, i.e., scenario CMMA, leads to a share of gas-fired power plants of $62 \%$, replacing completely PV and a huge part of wind power, compared to the EX selfish and CC selfish scenarios. While lowering the metal depletion target and thus increasing the relevance of the life-cycle GHG emissions, the relevance of gas-fired power plants decreases to $40 \%$ (scenario CMMM) and 18\% (scenario CMMR), respectively. Wind power and PV, compared to scenario CMMA, increasingly substitute gas-fired power plants. In the CMMM scenario, wind onshore contributes 15\%, PV $8 \%$, and wind offshore $2 \%$ to the electricity generation. In the CMMR scenario, the shares are $18 \%$ for PV, $22 \%$ for wind onshore, and $9 \%$ for wind offshore.

Summing up, RES power plants exhibit a higher metal depletion than fossil fuels-based or uranium-using power plants. The main reasons are the generally lower full load hours and the small size of renewable energy power plants per generated kWh electricity [4]. Thus, climate policy will promote wind power, due to its low life-cycle GHG emissions; 
whereas resource policy supports the use of gas-fired power plants with their comparable low life-cycle metal depletion. PV show higher life-cycle GHG emissions and higher metal depletion than wind power; thus a more relaxed resource policy is needed to achieve a noteworthy share of the electricity mix. Changing metal depletion targets will not affect the share of nuclear power and hydropower, as they show rather low metal depletion and low GHG emissions.

\section{Discussion}

The findings in Section 3 reveal the dynamics of different preferences regarding policy targets, and thus of the shape of policy packages, on the trade-offs between climate policy and resource policy. This evokes the question of how to overcome, or at least to smooth, the trade-offs between the policy targets.

An obvious possible option is to replace primary resources with secondary ones through increased recycling of metals.

The presented approach calculates life-cycle metal depletion induced by the transformation of the electricity system. Metal depletion measures the metal content-to-yield relation per extracted primary metal, measured in iron equivalents [7]. Any substitution of primary resources by secondary resources per generated kWh electricity would reduce the amount of metal depletion, potentially causing a diminishing effect on the trade-off between both policy targets; a sufficiently large substitution could even overcome the trade-off. For example, reducing the life cycle GHG emissions of the European electricity system between 2014 and 2050 by $84 \%$ would require substituting primary metals by about $58 \%$ [4] (Scenario High-RES Cen). More ambitious climate policy targets would demand a higher substitution rate. However, the required amount of secondary resources depends on the metal requirements of each technology used, and the mix of technologies of the electricity system and the upstream sectors.

Several factors limit the potential impact of an enforced recycling of metals on the trade-off. First, the possibility of downgrading during recycling of metals. Some recycled metal, like aluminum, shows worse properties in respect to stiffness, purity, deformability, and corrosion resistance than primary metals, limiting the possible applications [36,37]. Thus, primary metals will be necessary to install RES power plants. The substitution potential depends on the techno-economic conditions of using recycled metals, and the metal mix of both the electricity system and the upstream sectors.

Whereas the occurrence of downgrading limits the share of potentially replaceable metals, the electricity mix (which is the outcome of political and market decisions), and the induced structure of the upstream sectors as well as the electricity demand, determines the size of the sector-wide trade-off. These could overturn the recycling efforts described above.

The focus of this study is on the trade-off between climate change and metal requirements of "bulk" metals. However, next to bulk metals, critical metals, like rare earths, are increasingly becoming the focus of the energy transformation, as they are indispensable to most innovative RES technologies [38]. Although there is no common understanding regarding critical or strategic metals, mostly those are assigned to that group of metals which are essential for a technology with a high supply risk [39]. A growing share of RES technologies will intensify the trade-off between climate policy and resource policy. However, an in-depth analysis of the trade-off, comparable to the one presented, needs additional research, in particular a comprehensive database.

\section{Conclusions}

Considering the potential impacts of metal depletion on the future European decarbonized electricity system, these should affect the shape of policy packages regarding the energy transformation. Transforming the European electricity system to a RES-based one will affect the strategic position on the international metal markets, while the relevance of imported energy carriers to the EU electricity market would decrease notably [40]. The switch of strategic position could jeopardize the political aims of the EU Commission "to 
increase energy supply security, and to foster the sustainability and competitiveness of the European economy" ([38], p. 13) for challenging climate change [38].

This leads to the question of whether the trade-off could be smoothed, i.e., finding an electricity mix with less pronounced requirements for metals compared to 1990, while aiming at an ambitious GHG emission target to contribute to slowing down climate change. Considering in all scenarios a $\mathrm{CO}_{2}$ price of $160 € / \mathrm{tCO}_{2}$, our analysis shows that a reduction of the trade-off is possible, but the space for possible solutions is limited. An ambitious climate policy is only feasible when the resource policy is relaxed. To realize GHG emissions corresponding to an ambitious climate policy requires a specific mix of renewable energy sources in the electricity market, which would not allow installation of a sufficient number of low metal-depleting energy technologies, like gas-fired power plants, to reach a moderate or even ambitious resource policy target. Smoothing the trade-off will generally happen to the extent of either climate policy targets or resource policy targets.

One aim of the presented research is to make a first attempt to identify the possible space for defining policy packages considering both policy targets in the discussed frame. Additional research is needed to generate a better knowledge of how different policy targets interact, and thus to identify in a better way the space for political solutions. For this, a more detailed analysis of the shape of potential policy packages by considering potential policy instruments is recommended. Nevertheless, whereas climate policy targets are clearly communicated, this is lacking regarding other environmental and resource-related targets [41,42]. Consequently, a more in-depth analysis of policy packages would profit from more elaborated policy targets.

The study focused on one trade-off; a more systematic assessment of potential tradeoffs to minimize possible side effects would mean broadening the scope, in particular to consider, amongst others, land use change [4].

The findings of the study are based on a model focusing on electricity generation technologies. An enhanced inclusion of storage options and demand responses would have an impact on the results. Future studies will address this. Furthermore, from a methodological point of view, this study is subject to the following limitation. The nadir point should be selected out of the Pareto optimal solutions [34]. However, due to the model complexity, the nadir point in this paper is selected from the single optimization solutions in the payoff table. This should be improved in further studies.

Author Contributions: Conceptualization, L.X.; methodology, L.X., Z.W. and H.Ü.Y.; software, L.X., Z.W. and H.Ü.Y.; resources, data curation, L.X., Z.W. and H.Ü.Y.; writing-original draft preparation, L.X., Z.W. and H.Ü.Y.; writing—review and editing, W.-R.P., L.X., Z.W., H.Ü.Y., H.R., Y.G.; supervision, W.-R.P. All authors have read and agreed to the published version of the manuscript.

Funding: This research received no external funding.

Institutional Review Board Statement: Not applicable.

Informed Consent Statement: Not applicable.

Data Availability Statement: The data presented in this study are available in the article itself and the Appendix A of the article.

Acknowledgments: The authors would like to thank Patrick Jochem (DLR, Stuttgart Germany) for his inspiring suggestions; thank Lisa Schmieder (KIT ITAS, Karlsruhe Germany) for her valuable input with regard to policy packages; and thank the anonymous reviewers for their thoughtful comments and suggestions.

Conflicts of Interest: The authors declare no conflict of interest. 


\section{Appendix A}

Table A1. GHG emissions and metals depletion by technologies, 2015 and 2050.

\begin{tabular}{ccccc}
\hline Technology & \multicolumn{2}{c}{ GHG Emissions } & \multicolumn{2}{c}{ Metal Depletion } \\
\hline & \multicolumn{2}{c}{ kg CO $\mathbf{2}_{\mathbf{2}}$ eq/MWh } & $\mathbf{2 0 1 5}$ & $\mathbf{2 0 5 0}$ \\
\hline & $\mathbf{2 0 1 5}$ & $\mathbf{2 0 5 0}$ & 4.1 & 4.1 \\
Nuclear & 11.7 & 11.5 & 2.0 & 2.0 \\
Coal & 1227.3 & 1227.2 & 2.3 & 2.4 \\
Lignite & 1229.0 & 1221.2 & 3.2 & 3.2 \\
Gas & 488.4 & 488.4 & 1.7 & 1.7 \\
Hydro & 4.6 & 4.6 & 4.7 & 4.7 \\
Pump Storage & 56.8 & 56.8 & 5.2 & 2.7 \\
Biomass & 201.4 & 419.4 & 24.6 & 18.7 \\
Photovoltaic & 85.8 & 83.4 & 23.5 &
\end{tabular}

Table A2. Achieved levels regarding system expenditures, GHG emissions and metal depletion of each scenario in respect to the nadir point.

\begin{tabular}{cccc}
\hline Scenario & EX & CC & MD \\
\hline EX selfish & $0 \%$ & $31 \%$ & $84 \%$ \\
CC selfish & $100 \%$ & $0 \%$ & $100 \%$ \\
MD selfish & $0.0615 \%$ & $100 \%$ & $0 \%$ \\
CAMR & $0.0006 \%$ & $25 \%$ & $75 \%$ \\
CMMA & $0.0079 \%$ & $50 \%$ & $25 \%$ \\
CMMM & $0.0027 \%$ & $44 \%$ & $50 \%$ \\
CMMR & $0.0001 \%$ & $32 \%$ & $75 \%$ \\
\hline
\end{tabular}

\section{References}

1. Marques, A.C.; Fuinhas, J.A. Drivers promoting renewable energy: A dynamic panel approach. Renew. Sustain. Energy Rev. 2011, 15, 1601-1608. [CrossRef]

2. Burandt, T.; Xiong, B.; Löffler, K.; Oei, P.-Y. Decarbonizing China's energy system-Modeling the transformation of the electricity, transportation, heat, and industrial sectors. Appl. Energy 2019, 255, 113820. [CrossRef]

3. Solano Rodriguez, B.; Drummond, P.; Ekins, P. Decarbonizing the EU energy system by 2050: An important role for BECCS. Clim. Policy 2017, 17, S93-S110. [CrossRef]

4. Xu, L.; Fuss, M.; Poganietz, W.-R.; Jochem, P.; Schreiber, S.; Zoephel, C.; Brown, N. An Environmental Assessment Framework for Energy System Analysis (EAFESA): The method and its application to the European energy system transformation. J. Clean. Prod. 2020, 243, 118614. [CrossRef]

5. Berrill, P.; Arvesen, A.; Scholz, Y.; Gils, H.C.; Hertwich, E.G. Environmental impacts of high penetration renewable energy scenarios for Europe. Environ. Res. Lett. 2016, 11, 014012. [CrossRef]

6. Igos, E.; Rugani, B.; Rege, S.; Benetto, E.; Drouet, L.; Zachary, D.S. Combination of equilibrium models and hybrid life cycle input-output analysis to predict the environmental impacts of energy policy scenarios. Appl. Energy 2015, 145, 234-245. [CrossRef]

7. Goedkoop, M.; Huijbregts, M.; Heijungs, R.; De Schryver, A.; Struijs, J.; Van Zelm, R. ReCiPE 2008: A Life Cycle Impact Assessment Method Which Comprises Harmonised Category Indicators at the Midpoint and the Endpoint Level. 2008. Available online: https:/ / www.leidenuniv.nl/cml/ssp/publications/recipe_characterisation.pdf (accessed on 1 March 2021).

8. European Commission, Resource Efficiency and Recycling. Available online: https://ec.europa.eu/growth/sectors/rawmaterials/policy-strategy/resource-efficiency_en (accessed on 28 February 2021).

9. European Commission, Raw Materials Diplomacy. Available online: https://ec.europa.eu/growth/sectors/raw-materials/ specific-interest/international-aspects_en (accessed on 1 March 2021).

10. European Commission, Tackling the Challenges in Commodity Markets and on Raw Materials. COM (2011) 25. Available online: https: / / eur-lex.europa.eu/legal-content/EN/TXT/PDF/?uri=CELEX:52011DC0025\&from=EN (accessed on 1 March 2021).

11. Tuominen, A.; Tapio, P.; Varho, V.; Järvi, T.; Banister, D. Pluralistic backcasting: Integrating multiple visions with policy packages for transport climate policy. Futures 2014, 60, 41-58. [CrossRef]

12. Givoni, M.; Macmillen, J.; Banister, D.; Feitelson, E. From policy measures to policy packages. Transp. Rev. 2013, 33, 1-20. [CrossRef] 
13. May, A.D.; Kelly, C.; Shepherd, S.; Jopson, A. An option generation tool for potential urban transport policy packages. Transp. Policy 2012, 20, 162-173. [CrossRef]

14. Kessler, F.; Vesela, J.; Vencl, V.; Strnadova, D.; Sørensen, C.H.; Schippl, J.; Longva, F.; Ramjerdi, F.; Osland, O.; Givoni, M. Best Practice in Policy Package Design. Available online: http:/ / optic.toi.no/getfile.php/1316951-1301426656/Optic/Bilder\%20og\% 20dokumenter\%20internett/OPTIC\%20D4\%20Final.pdf (accessed on 5 March 2021).

15. Hertwich, E.G.; Gibon, T.; Bouman, E.A.; Arvesen, A.; Suh, S.; Heath, G.A.; Bergesen, J.D.; Ramirez, A.; Vega, M.I.; Shi, L. Integrated life-cycle assessment of electricity-supply scenarios confirms global environmental benefit of low-carbon technologies. Proc. Natl. Acad. Sci. USA 2015, 112, 6277-6282. [CrossRef]

16. Viebahn, P.; Lechon, Y.; Trieb, F. The potential role of concentrated solar power (CSP) in Africa and Europe-A dynamic assessment of technology development, cost development and life cycle inventories. Energy Policy 2011, 39, 4420-4430. [CrossRef]

17. Brown, N.; Fuss, M.; Xu, L. D6.3 Social, Environmental and External Cost Assessment Of future Energy Technologies and Future Energy Systems. Report for the REFLEX Project. 2019. Available online: http:/ / reflex-project.eu/ (accessed on 15 February 2021).

18. García-Gusano, D.; Iribarren, D.; Martín-Gamboab, M.; Dufour, J.; Espegrena, K.; Linda, A. Integration of life-cycle indicators into energy optimisation models: The case study of power generation in Norway. J. Clean. Prod. 2016, 112, 2693-2696. [CrossRef]

19. García-Gusano, D.; Martín-Gamboa, M.; Iribarren, D.; Dufour, J. Prospective Analysis of Life-Cycle Indicators through Endogenous Integration into a National Power Generation Model. Resources 2016, 5, 39. [CrossRef]

20. Rauner, S.; Budzinski, M. Holistic energy system modeling combining multi-objective optimization and life cycle assessment. Environ. Res. Lett. 2017, 12, 124005. [CrossRef]

21. Vandepaer, L.; Panos, E.; Bauer, C.; Amor, B. Energy System Pathways with Low Environmental Impacts and Limited Costs: Minimizing Climate Change Impacts Produces Environmental Cobenefits and Challenges in Toxicity and Metal Depletion Categories. Environ. Sci. Technol. 2020, 54, 5081-5092. [CrossRef]

22. Heinrichs, H.U. Analyse der langfristigen Auswirkungen von Elektromobilität auf das deutsche Energiesystem im europäischen Energieverbund; KIT Scientific Publishing: Karlsruhe, Germany, 2014.

23. Plötz, P.; Gnann, T.; Jochem, P.; Yilmaz, H.Ü.; Kaschub, T. Impact of electric trucks powered by overhead lines on the European electricity system and $\mathrm{CO}_{2}$ emissions. Energy Policy 2019, 130, 32-40. [CrossRef]

24. Fichtner, W. Strategische Optionen der Energieversorger zur $\mathrm{CO}_{2}$-Minderung: Ein Energie-und Stoffmodell zur Entscheidungsunterstützung. Ph.D. Thesis, Universität Karlsruhe (TH), Karlsruhe, Germany, 1999.

25. International Energy Agency. World Energy Outlook. 2016. Available online: https://www.oecd-ilibrary.org/energy/worldenergy-outlook-2016-en (accessed on 15 February 2021).

26. Deutsches Institut für Wirtschaftsforschung (DIW). Current and Prospective Costs of Electricity Generation until 2050, Research Report, Berlin. 2013. Available online: https://www.diw.de/documents/publikationen/73/diw_01.c.424566.de/diw_datadoc_ 2013-068.pdf (accessed on 2 February 2021).

27. Keles, D.; Yilmaz, H.Ü. Decarbonisation through coal phase-out in Germany and Europe-Impact on Emissions, electricity prices and power production. Energy Policy 2020, 141, 111472. [CrossRef]

28. S\&P Global Platts, World Electric Power Plants Database. March 2018. Available online: https://www.spglobal.com/platts /pt/ products-services / electric-power/world-electric-power-plants-database (accessed on 1 March 2021).

29. ISO. Environmental Management: Life Cycle Assessment: Principles and Framework; ISO: Berlin, Germany, 2006.

30. Treyer, K.; Bauer, C. Life cycle inventories of electricity generation and power supply in version 3 of the ecoinvent database-part I: Electricity generation. Int. J. Life Cycle Assess. 2016, 21, 1236-1254. [CrossRef]

31. Huijbregts, M.; Steinmann, Z.; Elshout, P.; Stam, G.; Verones, F.; Vieira, M.; Hollander, A.; Zijp, M.; Van Zelm, R. ReCiPe 2016: A Harmonized Life Cycle Impact Assessment Method at Midpoint and Endpoint Level Report I: Characterization; RIVM-report 2016-0104; Ministry of Health, Welfare and Sport: The Hague, The Netherlands, 2016.

32. Mavrotas, G. Effective implementation of the $\varepsilon$-constraint method in multi-objective mathematical programming problems. Appl. Math. Comput. 2009, 213, 455-465. [CrossRef]

33. Censor, Y. Pareto optimality in multiobjective problems. Appl. Math. Optim. 1977, 4, 41-59. [CrossRef]

34. Mavrotas, G. Generation of Efficient Solutions in Multiobjective Mathematical Programming Problems Using GAMS. Effective Implementation of the $\varepsilon$-Constraint Method. Available online: https:/ /www.gams.com/modlib/adddocs/epscm.pdf (accessed on 5 March 2021).

35. Parkinson, S.C.; Makowski, M.; Krey, V.; Sedraoui, K.; Almasoud, A.H.; Djilali, N. A multi-criteria model analysis framework for assessing integrated water-energy system transformation pathways. Appl. Energy 2018, 210, 477-486. [CrossRef]

36. Amini, S.H.; Remmerswaal, J.A.M.; Castro, M.B.; Reuter, M.A. Quantifying the quality loss and resource efficiency of recycling by means of exergy analysis. J. Clean. Prod. 2007, 15, 907-913. [CrossRef]

37. Hagelücken, C. Recycling of (critical) metals. In Critical Metals Handbook; Gus, G., Ed.; Wiley: Oxford, UK, $2014 ;$ pp. 41-69.

38. Moss, R.L.; Tzimas, E.; Kara, H.; Willis, P.; Kooroshy, J. Critical Metals in Strategic Energy Technologies. Assessing Rare Metals as Supply-Chain Bottlenecks in Low-Carbon Energy Technologies; Publications Office of the European Union: Luxembourg, 2011.

39. Graedel, T.E.; Gun, G.; Tercero Espinoza, L. Metal resources, use and criticality. In Critical Metals Handbook; Gus, G., Ed.; Wiley: Oxford, UK, 2014; pp. 1-19.

40. Eyl-Mazzega, M.-A.; Mathieu, C. The European Union and the Energy Transition. In The Geopolitics of the Global Energy Transition; Hafner, M., Tagliapietra, S., Eds.; Springer: Cham, Switzerland, 2020; pp. 27-46. 
41. European Parliament, Energy Policy: General Principles. Fact Sheets on the European Union. 2020. Available online: https: //www.europarl.europa.eu/ftu/pdf/en/FTU_2.4.7.pdf32 (accessed on 1 March 2021).

42. Bahn-Walkowiak, B.; Steger, S. Resource Targets in Europe and Worldwide: An Overview. Resources 2015, 4, 597-620. [CrossRef] 